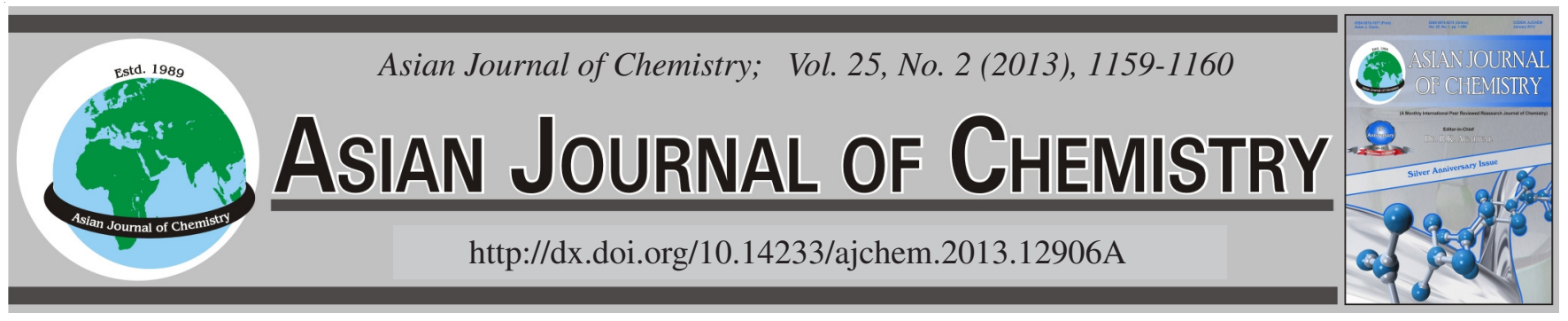

NOTE

\title{
Synthesis and Structural Characterization of N-Hydroxy-7-oxa-bicyclo[2,2,1]hept-5-ene-2,3-dicarboximide
}

\section{JIAN LI}

Department of Chemistry and Chemical Engineering, Weifang University, Weifang, 261061, P.R. China

Corresponding author: Tel: +86 536 8877561; E-mail: ljwfu@163.com

\begin{abstract}
The compound N-hydroxy-7-oxa-bicyclo[2,2,1] hept-5-ene-2,3-dicarboximide $\left(\mathrm{C}_{8} \mathrm{H}_{7} \mathrm{NO}_{4}, \mathrm{M}_{\mathrm{r}}=181.15\right)$ was synthesized and characterized by elemental analysis, ${ }^{1} \mathrm{H}$ NMR spectra, IR spectra and single crystal X-ray diffraction. The crystal belongs to orthorhombic, space group Pnma, with $\mathrm{a}=10.9505(11), \mathrm{b}=10.7263(10), \mathrm{c}=6.4005(4) \AA, \beta=90.00^{\circ}, \mathrm{V}=751.79(11) \AA^{3}, \mathrm{Z}=4, \mathrm{D}_{\mathrm{c}}=1.600 \mathrm{~g} / \mathrm{cm}^{3}, \lambda=0.71073 \AA$, $\mu\left(\mathrm{MoK}_{\alpha}\right)=0.131 \mathrm{~mm}^{-1}, \mathrm{~F}_{(000)}=376$. The final refinement gave $\mathrm{R}=0.0434, \mathrm{wR}\left(\mathrm{F}^{2}\right)=0.1074$ for 702 observed reflections with $\mathrm{I}>2 \sigma(\mathrm{I})$. The structure of the title compound comprises a racemic mixture of chiral molecules containing four stereogenic centres. X-Ray diffraction analysis reveals that the cyclohexane ring tends towards a boat conformation, the tetrahydrofuran ring and the dihydrofuran ring adopt envelope conformations.
\end{abstract}

Key Words: N-Hydroxy-7-oxa-bicyclo[2,2,1]hept-5-ene-2,3-dicarboximide, Synthesis, Structural characterization.

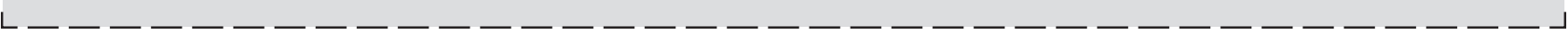

The imide moiety is an integral structural part of various important bioactive molecules such as fumaramidmycin, granulatimide, isogranulatimide and rebeccamycin. These molecules are reported to exhibit antitumor, antiinflammatory and antimicrobial activities ${ }^{1-3}$. 7-Oxa-bicyclo[2,2,1]hept-5ene-2,3-dicarboxylic anhydride has been widely employed in clinical practice, as it is less toxic and much easier to be synthesized $^{4,5}$. Its derivatives are also pharmacologically active $^{6}$. Furthermore, 7-oxa-bicyclo[2,2,1]hept-5-ene-2,3dicarboximide and its $\mathrm{N}$-substituent compounds have recently become an intense research topic in heterocyclic chemistry because of their antitumor, antivirus, analgesic, sedative and fungicidal activities ${ }^{7}$. In this paper, the title compound N-hydroxy7-oxa-bicyclo[2,2,1]hept-5-ene-2,3-dicarboximide was synthesized and its molecular structure was investigated by elemental analysis, ${ }^{1} \mathrm{H}$ NMR spectra, IR spectra and X-ray crystallographic techniques.

All the reagents were of AR grade and used without further purification. IR spectra (4000-400 $\left.\mathrm{cm}^{-1}\right)$, as $\mathrm{KBr}$ pellets, were recorded on a Nicolet FT-IR 510P spectrometer. ${ }^{1} \mathrm{H}$ NMR spectra were measured with a Bruker ALP 80 nuclear magnetic resonance spectrometer $\left(\mathrm{CD}_{3} \mathrm{COCD}_{3}\right.$ as solvent, TMS as internal standard).

7-Oxa-bicyclo[2,2,1]hept-5-ene-2,3-dicarboxylic anhydride was prepared in the previous job ${ }^{8-10}$. The synthesis of the title compound II is described below.
A mixture of exo-7-oxa-bicyclo[2,2,1]hept-5-ene-2,3-dicarboxylic anhydride $(0.83 \mathrm{~g}, 5 \mathrm{mmol})$ and hydroxylamine hydrochloride $(0.35 \mathrm{~g}, 5 \mathrm{mmol})$ in methanol $(15 \mathrm{~mL})$ was stirred for $5 \mathrm{~h}$ at room temperature and then refluxed for $1 \mathrm{~h}$. After cooling the precipitate was filtered and dried, the title compound was obtained. The product of $20 \mathrm{mg}$ was dissolved in methanol of $10 \mathrm{~mL}$. The solution was left for crystallization at room temperature. The single crystal suitable for X-ray determination was obtained by evaporation from the methanol solution after $6 \mathrm{~d}$.

Data collection and structure determination: A selected crystal of the title compound was mounted on a SMART CCD diffractometer. The reflection data were measured at $298 \mathrm{~K}$, using a graphite monochromator $\operatorname{MoK}_{\alpha}(\lambda=0.71073 \AA)$ radiation with an $\omega-2 \theta$ scan mode. The total reflections were 3609 with 702 independent ones $\left(R_{\text {int }}=0.0434\right)$, of which 620 were observed with $I>2 \sigma(I)$. Intensities were corrected for Lorentz and polarization effects and empirical absorption and all data were corrected using SADABB ${ }^{11}$ program.

The structure was solved by direct methods using SHELXS-97 ${ }^{12}$ program. All the non-hydrogen atoms were refined on $\mathrm{F}^{2}$ anisotropically by full-matrix least squares method. All hydrogen atoms were placed in the geometrically calculated positions. The contributions of these hydrogen atoms were included in the structure factor calculations. The atomic scattering factors and anomalous dispersion corrections 
were taken from International Table for X-ray crystallography ${ }^{13}$. The final least-square cycle gave $\mathrm{R}=0.0434$ and $\omega \mathrm{R}=0.1074$ $\left(\mathrm{w}=1 /\left[\sigma^{2}\left(\mathrm{Fo}^{2}\right)+(0.0497 \mathrm{P})^{2}+0.3094 \mathrm{P}\right]\right.$, where $\mathrm{P}=\left(\mathrm{Fo}^{2}+\right.$ $\left.\left.2 \mathrm{Fc}^{2}\right) / 3\right) . \mathrm{S}=1.181,(\Delta \rho)_{\min }=-0.239$ and $(\Delta \rho)_{\max }=0.194 \mathrm{e} / \AA^{3}$. CIF file containing complete information on the studied structure was deposited with CCDC, deposition number 848675 and is freely available upon request from the following web site: www.ccdc.cam.ac.uk/data_request/cif

The atomic coordinates and equivalent isotropic thermal parameters for the non-H atoms in the title compound are given in Table- 1 and the selected bond distances and bond angles in Table-2. A displacement ellipsoid plot with atomic numbering scheme is shown in Fig. 1 and a perspective view of the crystal packing in the unit cell in Fig. 2.

\begin{tabular}{|c|c|c|c|c|}
\hline \multicolumn{5}{|c|}{$\begin{array}{r}\text { TABLE-1 } \\
\text { TIC COORDINATTE }\end{array}$} \\
\hline Atom & $\mathrm{x}$ & $\mathrm{y}$ & $\mathrm{Z}$ & $\mathrm{U}(\mathrm{eq})$ \\
\hline $\mathrm{N}(1)$ & $6920(2)$ & 2500 & $3166(3)$ & $39(1)$ \\
\hline $\mathrm{O}(1)$ & $7882(2)$ & 2500 & $1780(3)$ & $54(1)$ \\
\hline $\mathrm{O}(2)$ & 6721(1) & $4622(1)$ & $3386(2)$ & $62(1)$ \\
\hline $\mathrm{O}(3)$ & 6724(2) & 2500 & $8089(3)$ & $47(1)$ \\
\hline $\mathrm{C}(1)$ & $6419(2)$ & 3591(2) & $3916(3)$ & $39(1)$ \\
\hline $\mathrm{C}(2)$ & $5452(2)$ & $3221(2)$ & $5485(3)$ & $34(1)$ \\
\hline $\mathrm{C}(3)$ & $5856(2)$ & $3508(2)$ & $7761(3)$ & $43(1)$ \\
\hline $\mathrm{C}(4)$ & $4810(2)$ & $3116(2)$ & $9150(3)$ & $48(1)$ \\
\hline \multicolumn{5}{|c|}{$\begin{array}{c}\text { TABLE-2 } \\
\text { OND LENGTHS }(\AA) \text { AND BOND ANGLES }\left({ }^{\circ}\right)\end{array}$} \\
\hline Bond & Length $(\AA)$ & & & Angle $\left({ }^{\circ}\right)$ \\
\hline $\mathrm{N}(1)-\mathrm{O}(1)$ & $1.377(3)$ & $\mathrm{O}(1)$ & 1)-C(1) & 121.91(10) \\
\hline $\mathrm{N}(1)-\mathrm{C}(1)$ & $1.378(2)$ & $\mathrm{O}(2)$ & 1)-N(1) & 124.96(18) \\
\hline $\mathrm{O}(2)-\mathrm{C}(1)$ & $1.203(2)$ & $\mathrm{O}(2)$ & 1)-C(2) & $128.33(17)$ \\
\hline $\mathrm{O}(3)-\mathrm{C}(3)$ & $1.455(2)$ & $\mathrm{N}(1)$ & 1)-C(2) & $106.72(15)$ \\
\hline$C(1)-C(2)$ & $1.512(2)$ & $\mathrm{O}(3)$ & 3)-C(4) & $101.75(15)$ \\
\hline$C(2)-C(3)$ & $1.553(2)$ & $\mathrm{O}(3)$ & $3)-C(2)$ & $100.04(14)$ \\
\hline$C(3)-C(4)$ & $1.510(3)$ & & - & - \\
\hline
\end{tabular}

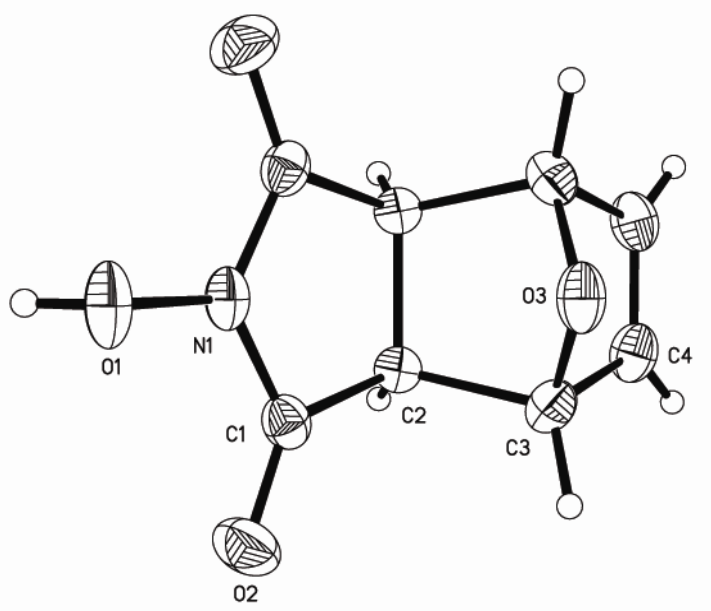

Fig. 1. Molecular structure with atomic numbering scheme

In the infrared spectrum, the broad absorption at 1771 and $1680 \mathrm{~cm}^{-1}$ is assigned to the stretching vibration of $\mathrm{v}(\mathrm{C}=\mathrm{O})$ of carbonyl group. The compound exhibits characteristic strong bands at $1600 \mathrm{v}(\mathrm{C}=\mathrm{C}), 1195 \mathrm{v}(\mathrm{C}-\mathrm{O}-\mathrm{C}) .{ }^{1} \mathrm{H}$ NMR $\delta: 5.78(\mathrm{~m}$, $2 \mathrm{H}, 2 \mathrm{CH}), 4.63$ (m, 2H, 2CH), 3.09 (d, 2H, 2CH), 1.99 (s, H,

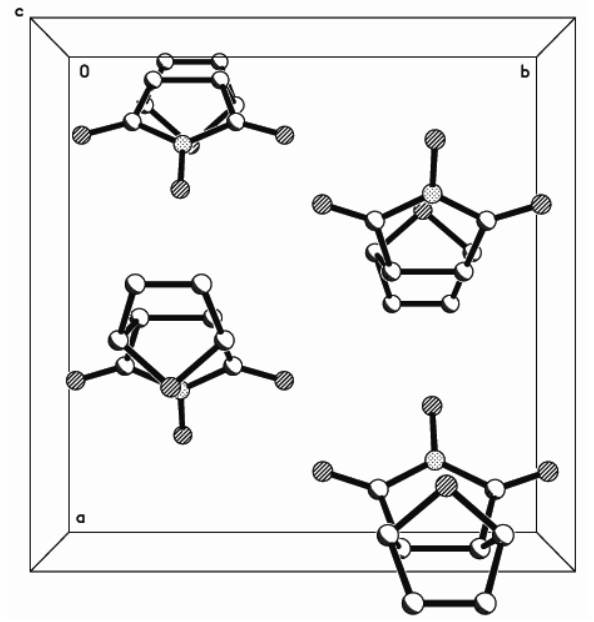

Fig. 2. View of crystal packing down the c-axis

$\mathrm{OH})$. Anal. calcd. (\%) for $\mathrm{C}_{8} \mathrm{H}_{7} \mathrm{NO}_{4}$ : C 53.04, H 3.87, N 7.74. Found (\%): C 53.11, H 3.88, N 7.72.

The structure of the title compound comprises a racemic mixture of chiral molecules containing four stereogenic centres. As seen from Fig. 1, the cyclohexane ring tends towards a boat conformation and the tetrahydrofuran ring and the dihydrofuran ring adopt envelope conformations. As seen from Table-2, the bond lengths and bond angles are as expected. And they are comparable to those in the similar compounds ${ }^{8-10}$. In the title compound, the $\mathrm{C}-\mathrm{C}$ bonds lengths [1.510(3)1.553(2) Å], except C4-C4 \#1 double bond length [1.321(4) $\AA]$, are longer than the normal single bond length. The degree of lengthening of the $\mathrm{C}-\mathrm{C}$ bonds in the title compound is in good agreement with that of corresponding $\mathrm{C}-\mathrm{C}$ bonds in N-phenyl-7-oxa-bicyclo[2,2,1]hept-5-ene-2,3-dicarboximide ${ }^{8}$, N-propyl-7-oxa-bicyclo[2,2,1] hept-5-ene-2,3-dicarboximide ${ }^{9}$ and N-2,3-dimethyl-5-oxo-1-phenyl-1 $\mathrm{H}$-pyrazol-4-yl-7-oxabicyclo[2,2,1]hept-5-ene-2,3-dicarboximide ${ }^{10}$.

\section{ACKNOWLEDGEMENTS}

This work was supported by Shandong Provincial Natural Science Foundation,China (No. ZR2009BL027).

\section{REFERENCES}

1. M.F. Brana, A. Gradillas, A. Gomez, N. Acero, F. Llinares, D. MunozMingarrro, C. Abradelo, F. Rey-Stolle, M. Yuste, J. Campos, M.A. Gallo and A. Espinosa, J. Med. Chem., 47, 2236 (2004).

2. S.M. Sondhi, R. Rani, P. Roy, S.K. Agrawal and A.K. Saxena, Bioorg. Med. Chem. Lett., 19, 1534 (2009).

3. J. Kossakowski and M. Jarocka, Farmaco, 56, 785 (2001).

4. $\quad$ L.P. Deng and Y.Z. Hu, J. Heterocycl. Chem., 44, 597 (2007).

5. L.P. Deng, F.M. Liu and H.Y. Wang, J. Heterocycl. Chem., 42, 13 (2005).

6. M.E. Hart, A.R. Chamberlin, C. Walkom, J.A. Sakoff and A. McCluskey, Bioorg. Med. Chem. Lett., 14, 969 (2004).

7. G. Goksu, N. Ocal and D.E. Kaufmann, Molecules, 15, 1302 (2010).

8. J. Li, Z.P. Liang and W.L. Zeng, Asian J. Chem., 23, 4918 (2011).

9. Z.P. Liang and J. Li, Asian J. Chem., 23, 4918 (2011).

10. Z.P. Liang and J. Li, Asian J. Chem., 25, 660 (2013).

11. G.M. Sheldrick, SADABS, Program for Empirical Absorption Correction of Area Detector Data, University of Gottingen, Germany (1996).

12. G.M. Sheldrick, SHELXTL V 5.1 Software Reference Manual, Bruker AXS, Inc., Madison, Wisconsin, USA (1997).

13. Siemens, SMART and SAINT, Area Detector Control and Integration Software. Siemens Analytical X-Ray Systems, Inc., Madison, Wisconsin, USA (1996). 